\title{
The Effect of Adding Dexmedetomidine or Fentanyl to Levobupivacaine for Ultrasound-guided Supraclavicular brachial plexus block in Upper Extremity Sugeries \\ Eissa R.E, Abo-EInassr L.M, Amin S.M.and Mohamed R.M
}

Anesthesiology and Surgical ICU Department, Faculty of Medicine, Tanta University

\begin{abstract}
Background: Supraclavicular brachial plexus block is one of the most effective anesthetic procedures in operations for the upper extremity. It has gained importance as regional anesthetic technique for surgical, diagnostic and therapeutic purpose in interventional pain management.

Aim: We aimed to study the effect of adding dexamedetomidine or fentanyl to levobupivacaine in ultrasound guided supraclavicular brachial plexus block in upper extremity surgeries as regard to onset and duration of sensory and motor block and postoperative pain.

Methods and Material: The study was carried out in Tanta University Hospital on 90 patients of 18-60 years old with ASA physical status I/II scheduled for elective surgery of upper hand. Patients were divided into three equal groups. Group A: was given $30 \mathrm{ml}$ of $0.5 \%$ levobupivacaine with fentanyl $100 \mu \mathrm{g}$. Group B: was given $30 \mathrm{ml}$ of $0.5 \%$ levobupivacaine with dexamedetomidine $100 \mu \mathrm{g}$. Group C: was given $30 \mathrm{ml}$ of $0.5 \%$ levobupivacaine with $1 \mathrm{ml}$ normal saline. The following data were measured for each patient: hemodynamic status (HR, MAP), onset of sensory and motor block, and duration of sensory and motor block, visual analogue score (VAS) and incidence of complications.

Results: Our results showed that no significant difference between three groups according to hemodynamic changes, while there was significant prolongation in duration of sensory and motor block, significant decrease in VAS score in group B compared to group A and C.

Conclusions: We concluded that the addition of dexmedetomidine was better than fentanyl when both used as adjuvants to levobupivacaine in ultrasound guided brachial plexus block as demonstrated by prolongation of duration of sensory block, improved quality of postoperative analgesia and provide of desirable sedation
\end{abstract}

Keywords: Supraclavicular brachial plexus-dexmedetomidine-levobupivacaine - upper extremity surgeries

\section{Introduction}

Supraclavicular brachial plexus block is one of the most effective anesthetic procedures in ndoperations for the upper extremity. The supraclavicular brachial plexus block has gained importance as regional anesthetic technique for surgical, diagnostic and therapeutic purpose in interventional pain management. It includes blocking of the brachial plexus where it is most compactly arranged, with less requirement of anesthetic solution and rapid onset of action ${ }^{1}$.

It provides ideal condition for surgery, maintains stable intraoperative hemodynamics and decrease vasospasm, oedema and postoperative pain.

The use of ultrasound guidance for regional anesthesia became popular owing to detection of anatomical variants, painless performance and more accurate needle placement. The needle tip can be guided toward the neurovascular bundle to avoid injury to arteries, veins and other adjacent structure. It also helps to monitor the spread of local anesthetic solution in the appropriate tissue planes and thereby reduce the incidence of pneumothorax, arterial puncture and direct nerve damage $^{2}$.

Levobupivacaine, a new local anesthetic having, similar pharmacological profile, but was shown to possess less cardiotoxicity when compared to bupivacaine ${ }^{3}$.

Dexamedetomidine is Apha-2 agonist combined with local anesthetics to extend the duration of regional anesthesia. There has always been a search for ideal adjuvants in peripheral nerve blocks that prolong the duration of analgesia with lesser adverse effects. Dexmedetomidine is 8(eight) times more selective towards $\alpha_{2}$ adrenoreceptors compared to clonidine ${ }^{4}$. Clinical studies have shown opioid sparing effects of dexmedetomidine when used intravenously along with decrease in inhalational anesthetic requirement ${ }^{5}$. In addition, it has been reported to improve quality of intrathecal and epidural anesthesia $^{6}$. However, very few clinical trials have 
studied the effect of dexmedetomidine in supraclavicular brachial plexus block.

Fentanyl is a powerful synthetic opiate analgesic similar to but more potent than morphine. The effects of opioids on regional blockade are controversial. The addition of opioids in brachial plexus block is reported to improve success rate and postoperative analgesia, by some authors ${ }^{8}$. Whereas, others have found no effect ${ }^{9,10}$.

\section{Aim and objectives}

The aim is to study the effect of adding dexamedetomidine or fentanyl to levobupivacaine in ultrasound guided supraclavicular brachial plexus block in upper extremity surgeries as regard to onset and duration of sensory and motor block and postoperative pain

\section{Patients and Methods}

The study was carried out in Tanta University Hospital on 90 patients of 18-60 years old with ASA physical status I/II scheduled for elective surgery of upper hand. Patients were divided into three equal groups. Group A: was given $30 \mathrm{ml}$ of $0.5 \%$ levobupivacaine with fentanyl $100 \mu \mathrm{g}$. Group $\mathrm{B}$ : was given $30 \mathrm{ml}$ of $0.5 \%$ levobupivacaine with dexamedetomidine $100 \mu \mathrm{g}$. Group $\mathrm{C}$ : was given 30 $\mathrm{ml}$ of $0.5 \%$ levobupivacaine with $1 \mathrm{ml}$ normal saline. The study was approved by the Ethics Board of Tanta University.

\section{Measurements:}

1. Hemodynamics of the patient; heart rate and mean arterial blood pressure will be assessed continuously during operation and was recorded pre-operative and 5,10,15,20,30,40,50,60 min after procedure.

2. Onset of sensory block.

3. Onset of motor block.

4. Duration of sensory and motor block.

5. Post-operative analgesia: Assessed by visual analogue score (VAS) for pain that ranged from $(0=$ no pain to $10=$ the worst imaginable pain $)$.

6. Adverse effects comprised bradycardia (HR <50 beats/min), nausea, vomiting, pneumothorax, hemothorax, toxicity from local anesthesia.

Statistical presentation and analysis was conducted by SPSS V.24. P value $<0.05$ was considered significant.

\section{Results}

There were no significant differences in demographic data among the three studied groups. There was significant decrease in heart rate in group II in comparison with group I \& III (20 min,
$30 \mathrm{~min}, 40 \mathrm{~min}, 50 \mathrm{~min}$ and $60 \mathrm{~min}$ ) after anesthesia. (P value $<0.001$ ) as shown in figure (1).

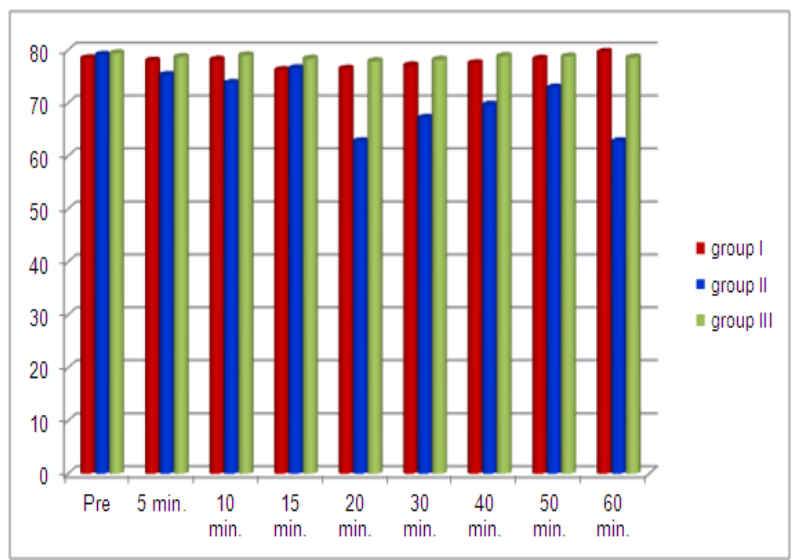

Figure (1): Comparison of heart rate changes in the three studied groups.

There was significant decrease in mean arterial blood pressure in group II in comparison with group I \& group III (20 min, $30 \mathrm{~min}, 40 \mathrm{~min}, 50$ min and $60 \mathrm{~min}$ ) after anesthesia (figure 2).

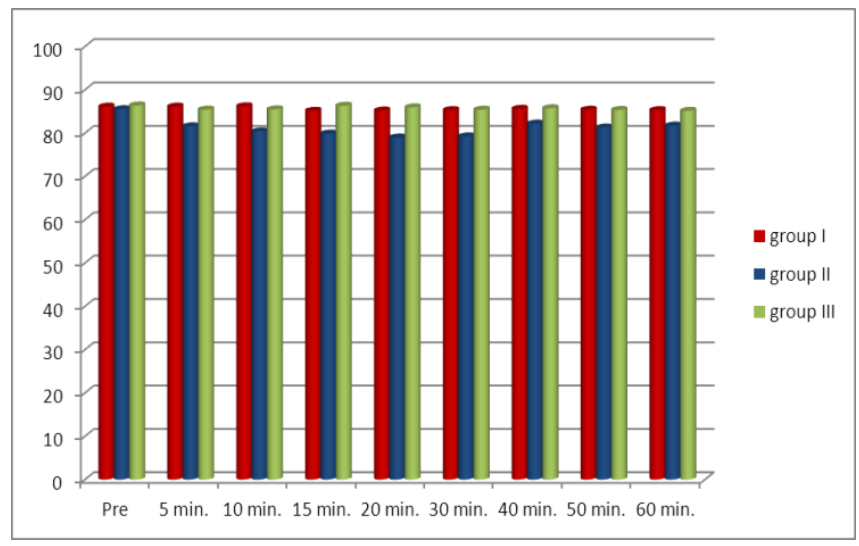

Figure (2): Mean arterial blood pressure changes in the three studied groups.

The onset of sensory block showed significant rapid onset in group II (6-8 $\mathrm{min})$ in comparison with group I (8-11 min) \& group III (10-12 min) as shown in figure (3)

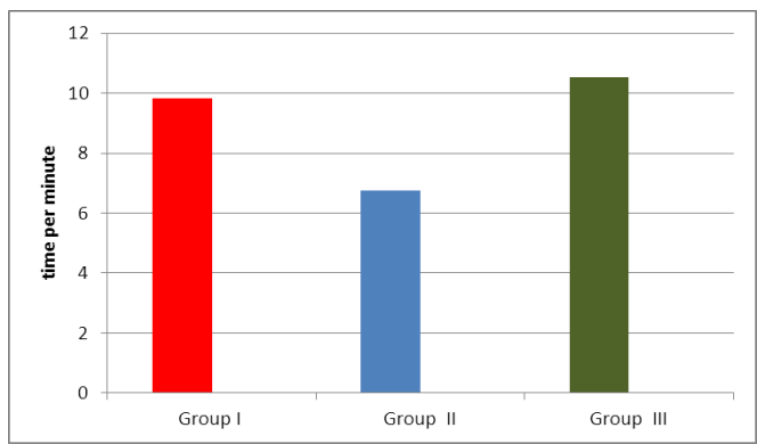

Figure (3): Onset of sensory block in the three studied groups. 
The onset of motor block showed significant rapid onset in group II (9-13 $\mathrm{min})$ in comparison with group I (13-15 $\mathrm{min})$ \& group III (15-17 $\mathrm{min}$ ) as shown in figure (4).

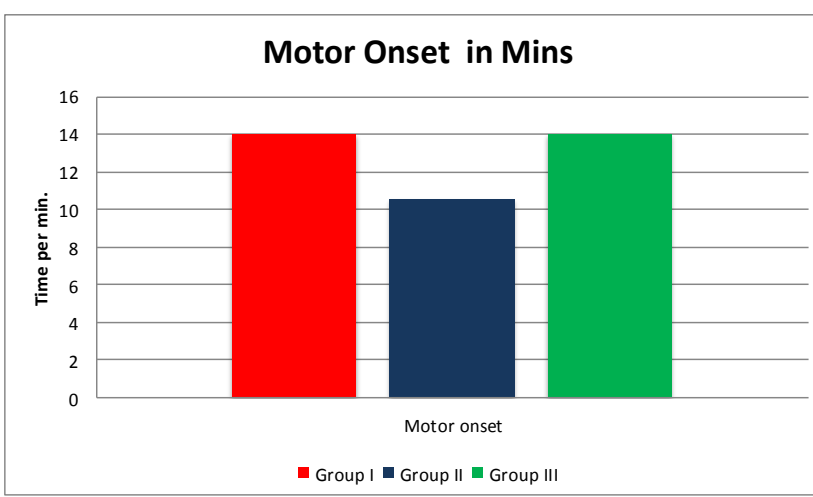

Figure (4): Onset of motor block ( $\mathrm{min}$ ) in the three studied groups.

The duration of sensory block showed significant increase in group II (822-840 $\mathrm{min})$ in comparison with group I (609-680 $\mathrm{min})$ \& group III (586$591 \mathrm{~min}$ ) as shown in figure (5)

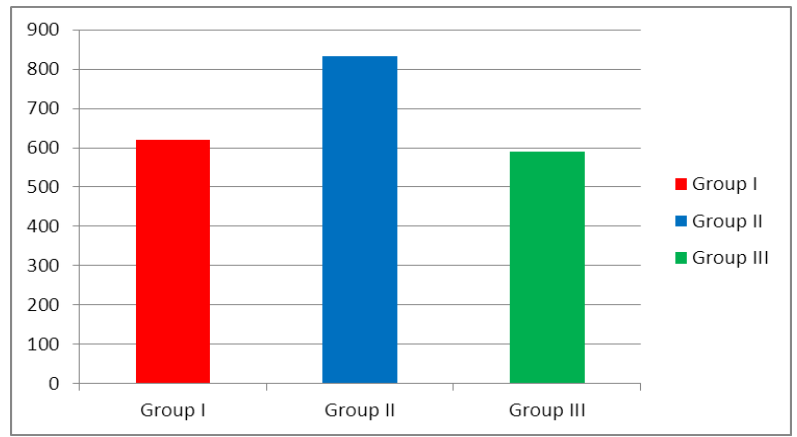

Figure (5): Duration of sensory block (min) in the three studied groups.

The duration of complete motor block showed significant increase in group II $(620-640 \mathrm{~min})$ in comparison with group I (509-580 min) \& group III (486-493 min) as shown in figure (6)

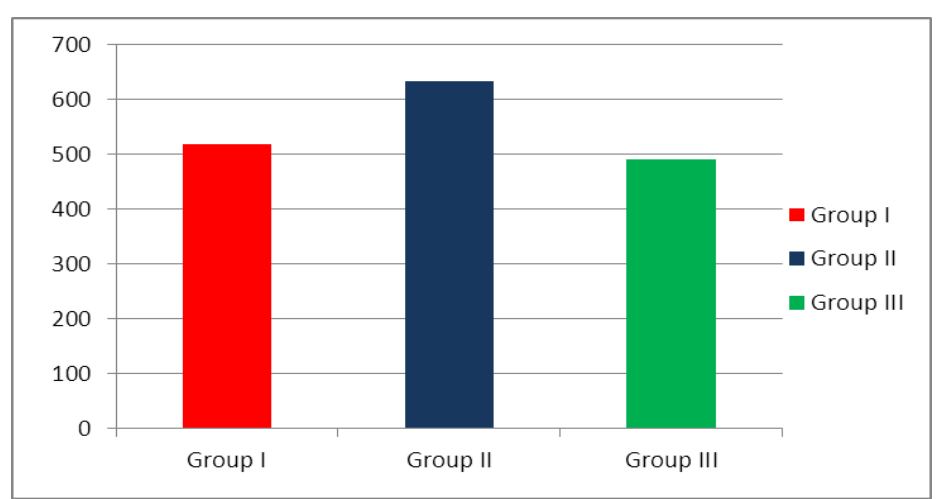

Figure (6): Duration of motor block (min) in the three studied groups.

The Visual Analogue Score (VAS) was significantly lower in group II in comparison with group I and group III (p value $<0.05$ ). In addition, the VAS was significantly lower in group I in comparison with group III ( $p$ value $<0.05$ ) as shown in figure (7).

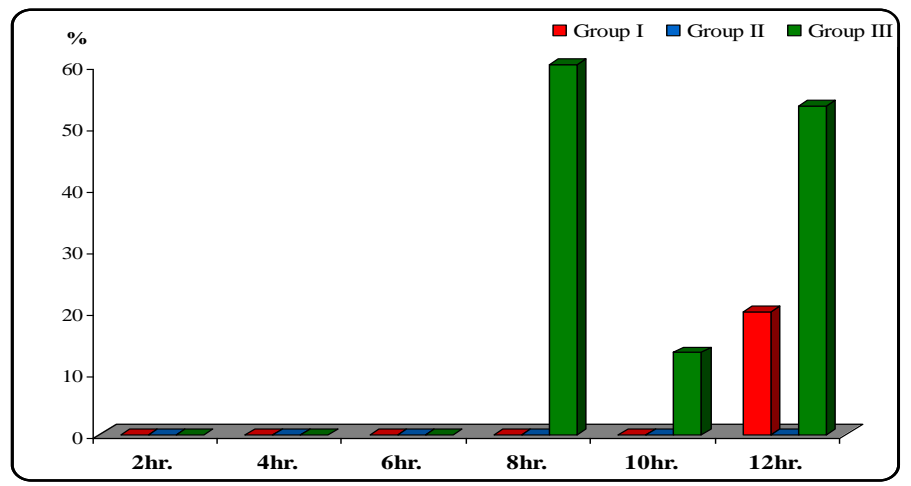

Figure (7): Visual analogue

scale in three studied groups

Nausea was observed in group III (one patient) ( $\mathrm{p}$ value $=0.36$ ). There was no vomiting, pneumothorax, hemothorax or toxicity from local anesthesia occuring in any group. The incidence of bradycardia was more in group II compared to group I and group III (20\% of patients developed bradycardia in group II) while $0 \%$ of patients in group I and group III.

The incidence of hypotension was more in group II compared to group I and group III 13\% of patients developed hypotension in group II while $0 \%$ of patients in group I and group III (table 1). 


\begin{tabular}{|c|c|c|c|c|c|c|c|c|}
\hline & \multicolumn{8}{|c|}{ Side effects } \\
\hline & \multicolumn{2}{|c|}{$\begin{array}{l}\text { Group I } \\
(n=30)\end{array}$} & \multicolumn{2}{|c|}{$\begin{array}{l}\text { Group II } \\
(\mathbf{n}=\mathbf{3 0})\end{array}$} & \multicolumn{2}{|c|}{$\begin{array}{l}\text { Group III } \\
(n=30)\end{array}$} & \multicolumn{2}{|c|}{ Chi-square } \\
\hline & $\mathbf{N}$ & $\%$ & $\mathbf{N}$ & $\%$ & $\mathbf{N}$ & $\%$ & $\mathbf{X}^{2}$ & $\begin{array}{c}\text { P- } \\
\text { value }\end{array}$ \\
\hline Nausea & 0 & 0.0 & 0 & 0.0 & 1 & 3.3 & 2.022 & 0.364 \\
\hline Bradycardia & 0 & 0.0 & 6 & 20.0 & 0 & 0.0 & 12.857 & $0.002 *$ \\
\hline Pneumothorax & 0 & 0.0 & 0 & 0.0 & 0 & 0.0 & 0.000 & 1.000 \\
\hline Hemothorax & 0 & 0.0 & 0 & 0.0 & 0 & 0.0 & 0.000 & 1.000 \\
\hline $\begin{array}{l}\text { Toxicity from L.A } \\
\text { drugs }\end{array}$ & 0 & 0.0 & 0 & 0.0 & 0 & 0.0 & 0.000 & 1.000 \\
\hline Vomiting & 0 & 0.0 & 0 & 0.0 & 0 & 0.0 & 0.000 & 1.000 \\
\hline Hypotension & 0 & 0.0 & 4 & 13.3 & 0 & 0.0 & 8.372 & 0.015* \\
\hline
\end{tabular}

Table (1): Complications in three studied groups.

\section{Discussion}

The brachial plexus is a complex network of nerves extending from the neck to the axilla providing both motor and sensory innervation to the upper limb. Understanding the structure of the brachial plexus remains a cornerstone for effective regional anesthesia. On the level of the supraclavicular fossa, the plexus is compactly arranged. The supraclavicular approach of the brachial plexus has a high success rate including blockade of the ulnar and musculocutaneous nerve which can be missed with the interscalene and axillary approach respectively ${ }^{1}$.

Adjuvants are drugs added to local anaesthetics (LA) for peripheral nerve blocks (PNBs) to fasten the onset of action and prolong the duration of analgesia. They may also allow for a reduction in the total volume of LA used. The interest in PNBs has increased during the last decade due to the availability of better needles, catheters and ultrasonography. A single dose of LA has a limited duration of action, hence various adjuvants are added to fasten the onset of anesthesia and prolong the duration of analgesia. Various adjuvant drugs like opioids, clonidine, dexamethasone, neostigmine and hyaluronidase have been evaluated in conjunction with local anesthetics to prolong the duration of analgesia ${ }^{12}$.

In this study, we evaluated the effect of dexmedetomidine versus fentanyl when added to levobupivacaine in ultrasonic guided supraclavicular brachial plexus block for patients undergoing upper limb surgeries. As regards demographic data, there was no statistically significant difference between three studied groups. As regards to hemodynamic changes ( heart rate, mean arterial blood pressure), they were decreased significantly in group II than group I and group III as dexmedetomidine is highly selective $\alpha_{2}$-adrenoceptor agonist. Stimulation of $\alpha_{2^{-}}$ adrenoceptors reduce central sympathetic output, resulting in increased firing of inhibitory neurons ${ }^{13}$. Dexmedetomidine has a biphasic, dose-dependent, cardiovascular response. The bolus dose of $1 \mu \mathrm{g} / \mathrm{kg}$ results in an initial increase in blood pressure and a reflex drop in heart rate. This response is seen more often with young and healthy patients. The increase in blood pressure is due to stimulation of the $\alpha-2 b$ receptors in vascular smooth muscle resulting in vasoconstriction ${ }^{14}$. The rise in blood pressure can be attenuated by a slow infusion and by avoiding bolus administration of the drug .This initial response lasts for 5 to 10 minutes and is followed by a slight decrease in blood pressure due to the inhibition of central sympathetic outflow. The presynaptic $\alpha-2$ receptors are also stimulated, thereby decreasing norepinephrine release, causing a fall in blood pressure and heart rate $e^{15,16}$.

Our study was in agreement with study of Esmaoglu et $\boldsymbol{a l} .{ }^{17}$, which was carried out on 60 patient scheduled for elective forearm and hand surgery. They were divided into two groups In group L $(\mathrm{n}=30), 40 \mathrm{~mL}(200 \mathrm{mg})$ of $0.5 \%$ levobupivacaine $+1 \mathrm{~mL}$ saline and in group LD (n $=30), 40 \mathrm{~mL}(200 \mathrm{mg})$ of $0.5 \%$ levobupivacaine + $1 \mathrm{~mL}$ dexmedetomidine were given, . In group LD bradycardia was observed in 7 patients, although there was no bradycardia in group L. Systolic and diastolic arterial blood pressure levels in group LD were significantly lower than those in group L.

Our results show significant decrease in the onset of sensory and motor block in group II than group I and group III and increase in the duration of sensory and motor block. Significant lower postoperative visual analogue score at $(2 \mathrm{~h}, 4 \mathrm{~h}, 6$ $\mathrm{h}, 8 \mathrm{~h}, 10 \mathrm{~h}$ and 12 hours) in patients who received a combination of dexmedetomidine and levobupivacaine (group II) than group I and group III, and in group I more than group III. 
We claim that our results were due dexmedetomidine (highly selective alpha $_{2}$ adrenergic receptor agonist). Mechanism by which alpha $_{2}$ adrenergic receptor agonists produce analgesia and sedation is not fully understood but is likely to be multifactorial. Peripherally, alpha agonists produce analgesia by reducing release of norepinephrine and causing alpha ${ }_{2}$ receptorindependent inhibitory effects on nerve fiber action potentials. Centrally, alpha 2 agonists produce analgesia and sedation by inhibition of substance $\mathrm{P}$ release in the nociceptive pathway at the level of the dorsal root neuron and by activation of alpha adrenoceptors in the locus coeruleus ${ }^{18,19}$.

In agreement with our study, Biswas et al. studied the effect of adding of dexmedetomidine to levobupivacaine in supraclavicular brachial plexus block $^{20}$. It was performed on 60 patients scheduled for elective forearm and hand surgery in group $\mathrm{L}(\mathrm{n}$ $=30) 35 \mathrm{cc}$ of levobupivacaine with $1 \mathrm{ml}$ of isotonic saline and in group LD $(n=30) 35 \mathrm{cc}$ of levobupivacaine with $1 \mathrm{ml}$ of (100 microgram) of dexmedetomidine was given. It was observed that sensory and motor duration were longer in group $\mathrm{LD}$ as compared to $\mathrm{L}$ and duration of analgesia was significantly longer in group LD as compared to group L.

Furthermore, a study by Arvinder et al. was carried out on 60 patient scheduled for elective forearm and hand surgery ${ }^{21}$. They were divided into 2 groups. Group I received $30 \mathrm{ml}$ of $0.5 \%$ levobupivacaine with $1 \mathrm{ml}$ of isotonic sodium chloride solution and Group II received $30 \mathrm{ml}$ of $0.5 \%$ levobupivacaine and $1 \mathrm{ml}(100 \mathrm{mcg})$ of dexmedetomidine for supraclavicular brachial plexus block. It was observed that the addition of dexmedetomidine to levobupivacaine significantly shortend the sensory and motor blockade onset time

Also, a study of Esmaoglu et al . concluded that sensory and motor block onset time were significantly shorter in levobupivacaine and dexmedetomidine group than the levobupivacaine only group ${ }^{17}$

Our results were in disagreement with the study by Kaygusuz et al. which was carried out on 64 patients scheduled to undergo forearm and hand surgery, in which an axillary block was used ${ }^{22}$. The patients were randomly divided into 2 groups. In group $\mathrm{L}$ patients $(\mathrm{n}=32)$, an axillary block was performed with $39 \mathrm{~mL}$ levobupivacaine $0.5 \%$ plus $1 \mathrm{~mL}$ of isotonic sodium chloride. In group $\mathrm{D}$ patients $(\mathrm{n}=32)$, an axillary block was performed with $39 \mathrm{~mL}$ levobupivacaine $0.5 \%$ and $1 \mathrm{~mL}$ dexmedetomidine $1 \mu \mathrm{g} / \mathrm{kg}^{-1}$ plus isotonic sodium chloride. They observed shortening of sensory block onset time whereas no shortening of motor onset time.

Our results showed significantly decrease in the onset of sensory and motor block in group I compared with group III and increase in the duration of sensory and motor block. Significant lower postoperative visual analogue score at $(2 \mathrm{~h}, 4$ $\mathrm{h}, 6 \mathrm{~h}, 8 \mathrm{~h}, 10 \mathrm{~h}$ and 12 hours), in patients who received a combination of fentanyl and levobupivacaine in group I more than group III.

\section{Conclusions:}

We concluded that the addition of dexmedetomidine was better than fentanyl when both were used as adjuvants to levobupivacaine in ultrasound guided brachial plexus block as demonstrated by prolongation of duration of sensory block, improved quality of postoperative analgesia without any considerable side effects.

\section{Acknowledgments:}

This research was carried out without funding.

\section{Conflicts of interest:}

No conflicts of interest declared.

\section{Authors' Contributions:}

All authors had equal role in design, work, statistical analysis and manuscript writing.

\section{References}

1-De Tran QH, Clemente A, Doan J et al. (2007): Brachial plexus blocks: A review of approaches and techniques. Can J Anesth. ,54: 662-74.

2-Kapral S, Krafft P, Eibenberger $K$ et al. (1994): Ultra sound-guided supraclavicular approach for regional anesthesia of the brachial plexus. Anesth Analg. , 78: 507-13.

3-Foster RH, Markham A (2000): Levobupivacine: a review of its pharmacology and use as a local anesthetic. Drugs, 59:551-79.

4-Ramio V, Juha M, Veijo S et al. (1998): Characterization of selectivity, specificity, and potency of medetomidine as $\alpha 2$ adrenoreceptor agonist. Eur J Pharmacol. , 150:9-14.

\section{5- Keniya VM, Ladi S, Naphade R (2011): Dexmedetomidine attenuates sympathoadrenal response to tracheal intubation and reduces perioperative anesthetic requirement. Indian $\mathbf{J}$ Anaesth. , 55:352-7.}


6- Kanazi GE, Aouad MT, Jabbour-K-Houry SI et al. (2006): Effect of low dose dexmedetomidine or clonidine on the characteristics of bupivacaine spinal block. Acta Anesth Scand., 50:222-7.

7-Congedo E, Sgreccia M, De Cosmo G (2009): New drugs for epidural analgesia. Curr Drug Targets , 10:696-706.

8- Nishikawa K, Kanaya N, Nakayama M et al. (2000): Fentanyl improves analgesia but prolongs the onset of axillarybrachial plexus block by peripheral mechanism. Anesth Analg. , 91:384-7.

9-Swami SS, Keniya VM, Ladi SD et al. (2012). Comparison of dexmedetomidine and clonidine (á2 agonist drugs) as an adjuvant to local anaesthesia in supraclavicular brachial plexus block: A randomised double-blind prospective study. Indian J Anesth. , 56:2439.

10- Chawda PM (2010): 200 ìg or clonidine 90 ìg as adjuvants to local anaesthetic agent in brachial plexus block via supraclavicular approach. J AnesthesiolClinPharmacol., 26:523-7.

11- Paul FW, Alejandro RF (2005): Regional anesthesia: Ambulatory (Outpatient) anesthesia: In Miller R,ed. Miller's Anesthesia. 6th ed. Elsevier: Churchill Livingstone.Philadelphia.

12- Bano F, Haider S, Tipu S (2004): Comparison of caudal bupivacaine midazolam for peri and postoperative analgesia in children. Journal of the college of physicians and surgeons-Pakistan, 14:65-8.

13- Marcia L. Buck, Pharm D (2016): FCCP Dexmedetomidine for sedation in the pediatric intensive care setting, pediatricpharma, 12(1).

14- Seyrek M, Halici Z, Yildiz O et al. (2011): Interaction between dexmedetomidine and alpha adrenergic receptors: emphasis on vascular actions. Journal of cardiothoracic and vascular anesthesia, 25(5):856-62.

15- Lee J(2012): Insight into the effects of dexmedetomidine on intraoperative hemodynamics and postanesthetic recovery speed. Korean journal of anesthesiology,62(2):111-2.

16- Afonso J, Reis FÉ (2012): Dexmedetomidine: current role in anesthesia and intensive care. Revistabrasileira de anestesiologia, 62(1):125-33.

17- Esmaoglu A, Yegenoglu F, Akin A(2010): Dexmedetomidine added to levobupivacaine prolongs axillary brachial plexus block. Anesth Analg. , 111:1548-51.

18- Eisenach JC, De Kock M, Klimscha W (1996): Alpha (2)-adrenergic agonists for regional anesthesia. A clinical review of clonidine (1984-1995).Anesthesiology, 85:655-74.

19- Guo TZ, Jiang JY, Buttermann AE (1996): Dexmedetomidine injection into the locus ceruleus produces antinociception. Anesthesiology, 84:873-81.

20- Biswas S, RK Das, Mukherjee G (2014): Dexmedetomidine an adjuvant to Levobupivacaine in supraclavicular brachial plexus block: A ramdomized double blind prospective study, Ethiopian Journal of health sciences, 24:3.

21- Pal Singh A., Mahindra M., Gupta $\mathbf{R}$ (2016): Dexmedetomidine as an adjuvant to levobupivacaine in supraclavicular brachial plexus block: A novel anesthetic approach, Anesth Essays Res. , 10(3): 414-9.

22- Kaygusuz K, Kol IO, Duger C (2012): Effects of adding dexmedetomidine to levobupivacaine in axillary brachial plexus block. CurrTher Res Clin. , 73:103-11. 